\title{
Management and Agricultural Technology Affecting to Longan Security in Thailand
}

\author{
Apichart Sudswang*, Sudawan Somjai, Sriparinya Toopgrajank \\ Suan Sunandha Rajabhat University, Bangkok, Thailand \\ Email: *aps1.thailand@gmail.com
}

How to cite this paper: Sudswang, A., Somjai, S. and Toopgrajank, S. (2018) Management and Agricultural Technology Affecting to Longan Security in Thailand. World Journal of Engineering and Technology, 6, 738-751.

https://doi.org/10.4236/wjet.2018.64048

Received: August 10, 2018

Accepted: October 7, 2018

Published: October 10, 2018

Copyright $\odot 2018$ by authors and Scientific Research Publishing Inc. This work is licensed under the Creative Commons Attribution-NonCommercial International License (CC BY-NC 4.0). http://creativecommons.org/licenses/by-nc/4.0/

\begin{abstract}
The objectives of this research are to study the management influences on Longan product, the value of Longan product with agricultural science and technology, and the public policy that affects on Longan product security. This study employs quantitative methods in analyzing the data collected from 400 Longan farmers in 3 provinces located in the northern region of Thailand: Chiang Mai, Chiang Rai, and Lamphun. The models were tested via Structural Equation Modeling or SEM and results indicate that Longan product management and public policy have positive effects on Longan security. Results also show that agricultural technology has a negative effect while the value of Longan product has no influence on the Longan security.
\end{abstract}

\section{Keywords}

Agricultural Technology, Longan, Management

\section{Introduction}

Longan is one of the Thailand's major economic crops which 80 percent of its production was exported annually [1]. It is a commercially important plant and is popular in Hong Kong and Singapore [2]. The cultivated area of Longan in Thailand is more than 1 million rais or approximately 400,000 acres. The data from 2009 to 2016 have shown that the cultivated area was continuously expanded. In 2016, the production of Longan was about 721,689 metric tons from a planted area of 1,056,277 rais, with the average rate of yields of 683 kilograms per rai. The Longan planted area in Thailand in 2012, including the area in the 8 northern provinces, counted as 1,013,329 rais. Most of them located in the northern part of Thailand of which counted as 869,227 rais, or 85 percent of the total national planted area. The top 3 provinces producing Longan, all in the 
northern region, include Chiang Mai, Lamphun and Chiang Rai.

The export of fresh Longan and its processed products such as dried, canned and frozen Longan, science and technology has been employed to help managing the Longan products throughout the process, ranging from upstream, midstream to downstream, including the supply chain management. The upstream activities refer to the Longan manufacturing plant and storage that focuses on value chain which are type of plants, seed, planting process, and proper care. The activities also include the method of creating the plant with a strong root system aiming for the plant to have good growth, and good soil that is appropriate for the plant, planting soil management, efficient watering, pest management, and efficient usage of production factor [3].

Ministry of Science and Technology (MoST) thus manages the output with fully-integrated system of science and technology. In order to identify the cultivated area (upstream) that can be inspected, monitored, and fostered the farmers' crops, they start their system by using the information from the satellite which belongs to the Geo-Informatics and Space Technology Development Agency (GISTDA). In addition, Thailand Institute of Nuclear Technology (TINT) also employs gamma irradiation to control the pest which helps extend shelf life of products. Moreover, Thailand Institute of Scientific and Technological Research (TISTR) creates the fumigation with sulfur dioxide, applied to destroy the microbial contamination, and prolong the shelf life of Longan while retaining the original Longan skin color. Lastly, the MoST assigned the National Science and Technology Development Agency (NSTDA) to transfer knowledge of the Longan production technology in the form of Longan Production Fully-Integrated Technology Center, targeting to develop Longan production system with quality, output rate, and environment in the real area.

Therefore, the MoST, a unit responsible for research, development and knowledge management, has created the integration plan to drive the development and management of Thai tropical fruits, both on quantitative and qualitative sides. The plan is based on science, technology, and innovation knowledge, integrated the operations among the MoST-controlled and other agencies. Up until now, the MoST already launched a pilot project that elevated both the production level and qualified Longan marketing system in the 5 northern provinces: Chiang Rai, Chiang Mai, Lamphun, Payao and Nan, as a readiness preparation responding to the free competition at the time of ASEAN Economic Community (AEC) inception. Meanwhile, the MoST has speeded up its work in integrating research of science, technology, and innovation in order to upgrade the production level and marketing system of Longan, among upstream, midstream and downstream. For the upstream, the focus is on applying the GIS map to manage the Longan farm-zone management, including farmer registration and the agricultural technology transfer to enable the certification of Good Agriculture Practices (GAP) from the Department of Agriculture, given that they already specified the rules and regulations of fruit inspection such as Durian, Longan, Orchid, Pineapple, Pomelo, Mango, and Tangerine. The rules and regulations 
follow the international GAP which are: 1) Using water drawn from clean water resources 2) Planting in germ-free, non-toxic healthy soil 3) Using and storing fertilizer and chemicals properly 4) Monitoring the quality control plan 5) Exploring, preventing, and controlling pests correctly 6) Harvesting crops with the right methods at the right time 7) Moving and storing the output with cleanliness and safety 8) Recording every step of the process in order to use as standard of agricultural production at the farm level nationwide.

\section{Research Objectives}

To study the influence of the Longan product management, value of Longan product, agricultural science and technology and public policy on the Longan security.

\section{Literature Review and Conceptual Framework}

\subsection{Conceptual Framework and Theory of Food Security}

Food and Agricultural Organization (FAO) has defined Food Security as a situation that everyone at any time has both the physical and economic ability to access food with sufficiency, safety and high nutrient-density. This will meet with their dietary needs and food preferences in order to create life with good energy and health. Food security has 4 elements; 1 ) food availability refers to the availability of food quantity and quality that is sufficient, both from domestic production or import, including food aid, 2) food access refers to the accessibility to the food or resource that has appropriate nutrition, 3) food utilization refers to usage of food with enough food quantity, clean water for drinking and other consumption, good sanitation in order to obtain valuable nutrition, and physical livelihood that is sufficiently fulfilled, and 4) food stability refers to the situation of which people, household, and individual can access to sufficient food all the time without any risk involving food inaccessibility resulting from the sudden crisis such as economic crisis or weather condition or cyclical incident like seasonal food instability. By this, it means that food security covers both dimensions, the sufficiency and accessibility of food [4].

In Thailand, National Food Committee Act B.E. 2551 defined food security as food with accessibility that is sufficient for the domestic consumption of the citizen, food that is safe, and food that has suitable nutrition according to group age. It aims to create well-being and supportive food production system, and to maintain both balanced ecosystem and the existence of natural food resources of the nation, either under the normal circumstance or even under disasters, or terrorist attacks relating to food.

Global Food Security Index (GFSI) has 3 categories; 1) affordability, 2) availability, and 3) quality and safety.

For the food security research conducted in Thailand, prior research work has applied FAO's food security framework to create food security standard to measure food security in the northern region of Thailand [5]. The criteria and 
indicators are as follows:

1) Longan availability has 3 indicators which are a) ability to produce food, b) readiness to procure clean water, and c) quantity of Longan output.

2) Accessibility to Longan has 3 indicators which are a) ability to consume Longan, b) ability to use natural resources, and c) product sharing.

3) Longan quality and safety has 3 indicators which are a) standard of Longan management, b) Longan quality, and c) food safety.

\subsection{Public Policy (Longan Policy or LOP)}

From the changes in the globalization age, challenges faced by agricultural sector have been diverse such as an inclined trend of farming labor in the agricultural sector, aging society entering, profession instability, high debt for some group of farmers, lack of arable land, falling price of agricultural products, natural disaster, and deteriorating agricultural resources, etc. In order to overcome these challenges, Thai government has identified 4 strategies for this agriculture development plan in the twelfth national economic and social development plan (2017-2021). The 4 strategies are:

Strategy \#1: Strengthen the farmers and their institutions. Strategy \#2: Improve efficiency of the agricultural product management and supply chain. Strategy \#3: Enhance competitive advantage with technology and innovation. Strategy \#4: Manage agricultural resource and environment with balance and sustainability.

For the strategy to drive the policy that aims to improve quality of life for the farmers, the Ministry of Agriculture and Cooperatives has specified the following approaches [6]; 1) Strengthen the farmers and their institutions 2) Improve efficiency and upgrade agricultural standard 3) Enhance competitive advantage with technology and innovation 4) Use of resource with balance and sustainability and avoid damaging the environment, and 5) Develop human resource to become smart officer.

Referring to the aforementioned Longan public policy, the researcher synthesized and argued that the public policy should be considered in the dimension trying to strengthening the farmers and environmental-friendly agriculture.

1) Strengthening the farmers includes:

a) Develop a farmer to become a smart farmer: according to the Strategy \#3 development and human potential creation indicating the potential improvement of people for a lifetime (the 20-Year National Strategy) and the 12th National Economic and Social Development Plan; Strategy \#1 the 12th National Economic and Social Development Plan (2017-2021) with the Ministry of Agriculture and Cooperatives specified their strategy in driving the policy to improve quality of life for the farmers by strengthening farmers and their institutions, as well as to develop a farmer to become a smart farmer in various aspects [7].

b) Do the collaborative farming, in order to enhance efficiency and improve standard of agriculture in upgrading to the quality agricultural products, such as 
GAP, GMP or organic farming, especially collaborative farming. A collaborative farming manager has to be a backbone to gather the members together in order to cooperate in operating, setting rules and standards in managing collaborative farming [7].

c) Build and connect farmers' network. Since community enterprise comes from the cooperation of the farmers' housewives and profession promotion group with experience, knowledge, expertise, and skill in adjusting the quality of Dried Golden Longan, with diverse systems and production methods, packaging improvement, finding the markets and distribution channels generates not only the income for the group but also the capacity to become self-reliant. They can also create products with their community's raw materials, resources and local wisdom.

2) Environmental-friendly agriculture includes:

a) Organic agriculture promotion. It covers the holistic production management that promotes and enhances the good condition of ecosystem, including biodiversity and soil biological diversity [4].

b) Water management.

c) Reduction of greenhouse glass emission. To support environmental-friendly growth for sustainable development, there has to be rules to support the growth as well as the development of measures and mechanisms to promote reduction of a greenhouse gas emission in all sectors (12th National Economic and Social Development Plan (2017-2021)).

\subsection{Longan Management Concept (Management of Longan or MoL)}

Longan products in its season, for some cases, has to face with marketing problems since the Longan product comes out at the same time, resulting in falling price. However, the out-of-season Longan products have to face with the production problems and the forced-to-bloom Longan flower does not match the target. The sustainable solutions need both cost management and production efficiency enhancement with the operation of production technology. As a result, the Longan farmers can get a better return [8].

Several scholars have given the definition of management of Longan or MoL in many dimensions. The researcher has synthesized and viewed that Longan management should be considered in the dimension of production management and market system development. Most of the scholars have given the definitions of both dimensions as follows.

1) Floral induction of Longan using Potassium Chlorate $\left(\mathrm{KClO}_{3}\right)$. Floral induction has made off-season Longan successful and has been extended all over the world [9]. While using highly-concentrated Potassium Chlorate can cause toxic in plant, applying low concentrated Potassium Chlorate can induce flower in Longan within 30 - 35 days afterward. Potassium Chlorate $\left(\mathrm{KClO}_{3}\right)$ thus plays an important role in flowering process since it helps produce Longan all year 
round [10].

2) Plant training and pruning control. Training and pruning clearly affect the quality grade of Longan. The flat shape has significantly given Longan fruits a significantly greater size as well as good color skin, all of which lead to a higher price of Longan. As a result, the flat-shaped Longan tree gives better economic returns, generating a higher income per tree, while, cylinder shape grows faster [11].

3) Production cost. The production system in agricultural sector still relies on imported production factors; therefore, the production cost is high, while agricultural land is limited and used for other purposes. In order for Longan farmers to receive a better return, the sustainable solutions needs both cost management and production efficiency enhancement with the operation of production technology [8].

4) Transportation and service. The environmental factors that play important roles are infrastructure, transportation, and service. Everything must be coordinated in working in concert with efficiency and speed, together with standardized management system and mutual trust among groups [12].

5) Distribution center. It refers to the supply-chain management for agricultural product and an efficient response to the customers' needs. Throughout the chain, starting from the producer, to product compiling, running from the middleman passing through the international market distribution channel, or domestic channel, the operation has been synchronized in responding among each other and pass on the information efficiently [12].

6) Mutual Integration with the key Ministry. In order to lay out a system to be a management system in the area, or called as "Single Command", a center to broadcast news and information has been set to enable the mutually integrated operation [6].

\subsection{Concepts of Agricultural Science and Technology or AST}

In collaboration between the Ministry of Agriculture and Cooperatives and Geo-Informatics and Space Technology Development Agency (GISTDA) to apply the science and technology to the agricultural products, a project to solve the Longan product problems was implemented in order to make it work from the upstream, midstream to the downstream of Longan products, resulting in a better quality of Longan. To keep Longan fresh, enzymatic browning inhibitors and a reduction in metabolic rate which prevents spoilage and sterilizes are introduced [13].

There are several ways to keep Longan fresh, including the followings:

1) Sulfur Dioxide Fumigation $\left(\mathrm{SO}_{2}\right)$. Sulfur dioxide fumigation is employed to control the pest. Sulfur dioxide is efficient in destroying the microbial contamination, prolong the shelf life of Longan while retaining the original Longan skin color. However, the problem of sulfur dioxide residues on fresh Longan, exceeding the standard specified by China, and other countries like USA, causes 
the rejection of fruits fumigated with $\mathrm{SO}_{2}$, turning out to be constraints in exporting Thai Longan [14].

2) Hydrochloric Acid Fruit Dipping. $\mathrm{HCl}$ acid dipping is discovered from research that aims to find a new technology to replace $\mathrm{SO}_{2}$ fumigation in order to help extend a storage life of Longan. It was found that the acid treatment works best if the fruits were stored at $2-5$ degree Celsius. Moreover, this method gives low residues on fresh Longan which is safe for consumers and accepted by both exporters and consumers.

3) Irradiation. Irradiation can control all kind of pests. It comes to a decision to pilot projects conducting for 6 fruits: Longan, Lychee, Mangosteen, Rambutan, Pineapple, and Mango, and later adding on Dragon fruit. Irradiation is capable of controlling, eliminating, and preventing reproduction all the pests that the United States does not want, such as Golden Fruit fly. At the same time, irradiation can help extend food shelf life. The electromagnetic wave used in the process is similar to a bright sunlight, as when the food is edible after being sun-dried.

World Health Organization (WHO), Food and Agriculture Organization of the United Nations (FAO), and International Atomic Energy Agency (IAEA) have concluded the results from the safety test of the irradiation. For the food that is irradiated, if its absorbed-dose does not exceed $1 \mathrm{kGy}$, food safety test will not be required. When comparing to the dose of radiation that the USA allows for imported fruits of only $400 \mathrm{~Gy}$, it is 25 times less than the standard. As a result, many countries are confident in its quality and already initiate their demands.

4) Hexanal Fumigation. Its effect can cease the microbial contamination that causes the Longan post-harvest spoilage [15].

5) Packaging. The freshness of Longan can be maintained for long by using the "in-fresh bag for Longan" of which the film used to make the bag to maintain its freshness has special qualification in controlling gas diffusion (Oxygen and Carbon Dioxide) and vapor efficiently. As a result, the duration of Longan freshness can be extended and the quality of Longan can be well preserved.

\subsection{Concept of Value of Longan or VoL}

Several scholars have defined value of Longan in various dimensions; therefore, the researcher synthesized and viewed that the quality of Longan product should be considered in the dimension of Longan fruit and price. Both dimensions have been genuinely defined by most scholars which are as follows:

1) Longan fruit consists of 2 indicators which are a) being an herbal ingredient [16] and $b$ ) being processed by diverse methods [17].

2) Longan price consists of 2 indicators which are a) good earning [2] and b) domestic and international trade [18].

\subsection{Conceptual Framework}

The schematic diagram of a conceptual framework of this research is depicted in Figure 1 and is discussed elaborately in Section 5.1. 


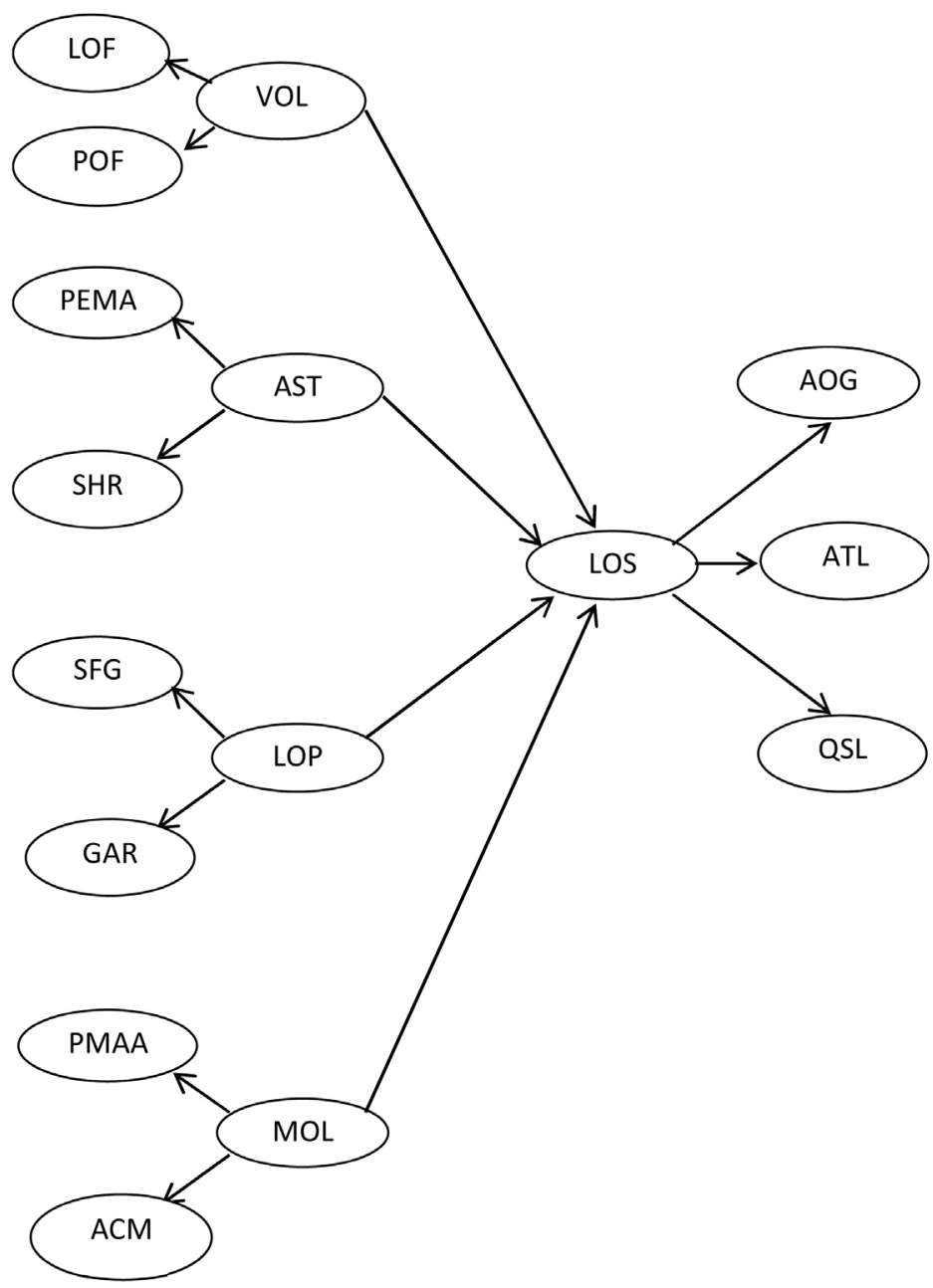

Figure 1. Longan security's conceptual framework.

\section{Research Methodology}

\subsection{Scope of Research}

400 Longan farmers in 3 provinces in the northern region: Chiang Mai, Chiang Rai, and Lamphun were included in this study. The data collection period was during September 30, 2017 to December 31, 2017.

\subsection{Research Hypothesis}

Longan product management, value of Longan product, agricultural science and technology, and public policy affect Longan security.

\subsection{Research Methodology}

The target population is Longan farmers located in 3 provinces in the northern region of Thailand. There are 48,108 households in Chiang Mai, 6353 households in Chiang Rai, and 35,821 households in Lamphun, a total of 90,282 households (Longan farmers' data from Chiang Mai, Chiang Rai, and Lamphun in 2016). The sampling method following the formula of Taro Yamane [19] was 
employed to determine the sample size of the research at $95 \%$ confidence level. As a result, the sample size is 398 samples which are rounded to 400 samples.

A questionnaire was used in this study, and Index of Item-Objective Congruence (IOC) was used so as to find the content validity. The IOC scores are higher than 0.5 in every item of questionnaires. For the reliability of measures, the value of Cronbach's alpha coefficient is between $0.700-0.974$. The structural equation modeling or SEM was used to estimate the model.

\section{Results and Discussions}

\subsection{First Order Equations}

From the conceptual framework, the second-order and the first-order latent variables can be written as first-order equations of each second-order latent variable for 5 models, a total of 11 equations. The writer proposed 11 first-order equations with the statistical values as follows:

The first set: Longan security (LOS) is estimated from 3 first-order latent variables: 1) Availability of Longan (AOG) 2) Accessibility to Longan (ATL) and 3) Quality and Safety of Longan (QSL). The equations measuring first-order latent variables can be written as follows:

$$
\begin{aligned}
\mathrm{AOG}= & 0.930 * \mathrm{LOS}, R^{2}=0.865 \\
\mathrm{ATL}= & 0.903 * \mathrm{LOS}, R^{2}=0.816 \\
& (0.152) \\
& 8.193 \\
\mathrm{QSL}= & 0.504 * \mathrm{LOS}, R^{2}=0.353
\end{aligned}
$$

From Equations (1) to (3), the findings indicate that availability of Longan, accessibility to Longan, and quality and safety of Longan are first-order latent variables of Longan security.

The second set: Value of Longan (VOL) is estimated from 2 first-order latent variables which are 1) Longan fruit (LOF) and 2) Price (POF). The equations measuring the first-order latent variables can be written as follows:

$$
\begin{aligned}
& \mathrm{LOF}=0.451 * \mathrm{VOL}, R^{2}=0.203 \\
& \mathrm{POF}=-0.349 * \mathrm{VOL}, R^{2}=0.122
\end{aligned}
$$

$$
-4.692
$$

From Equations (4) and (5), the findings indicate that Longan fruit and price are the first-order latent variables of Value of Longan.

The third set: Agricultural Science and technology (AST) is estimated from 2 first-order variables which are 1) Pest Elimination Management (PEM) and 2) Fumigation and Irradiation (SHR). The equations measuring the first-order latent variables can be written as follows: 


$$
\begin{aligned}
& \mathrm{PEM}=0.996 * \mathrm{AST}, R^{2}=0.992 \\
& \mathrm{SHR}=0.867 * \mathrm{AST}, R^{2}=0.752
\end{aligned}
$$

From Equations (6) to (7), the findings indicate that Pest Elimination Management, and Fumigation and Irradiation are the first-order latent variables of Agricultural science and technology.

The fourth set: Longan policy is estimated from 2 first-order variables which are 1) Strengthening Longan Farmers (SFG) and 2) Environmental-friendly Agriculture (GAR). The equations measuring the first-order latent variables can be written as follows:

$$
\begin{aligned}
\mathrm{SFG} & =0.778 * \mathrm{LOP}, R^{2}=0.606 \\
\mathrm{GAR} & =0.989 * \mathrm{LOP}, R^{2}=0.978
\end{aligned}
$$

From Equations (8) to (9), the findings indicate that Strengthening Longan Farmers and Environmental-friendly Agriculture are first-order latent variables of Longan policy.

The fifth set: Longan Product Management (MOL) is estimated from 2 first-order variables which are 1) Production Management (PMA) and 2) Agricultural Marketing (ACM). The equations measuring the first-order latent variables can be written as follows:

$$
\begin{aligned}
\mathrm{PMA}= & 0.997 * \mathrm{MOL}, R^{2}=0.995 \\
& (0.178) \\
& 5.349 \\
\mathrm{ACM}= & 0.97 * \mathrm{MOL}, R^{2}=0.813
\end{aligned}
$$

From Equations (10) to (11), the findings indicate that Production Management and Agricultural Marketing are first-order latent variables of Longan Product Management.

Regarding the correlation analysis among variables, the researcher has presented in the structural model in the form of standardized regression coefficient which can be seen in Figure 2.

From Table 1, the findings indicate that the results after adjusting the model; every fit index is totally considered more satisfactory than the previous model. Also, every fit index passes the criteria of fit indices of which the scholars have developed, identifying that the empirical data of the model is a good fit.

The result from Figure 2 can be written into structural equations as follows.

The effect of Longan product management, value of Longan, agricultural science and technology, and public policy on Longan security can be written into following structural equation.

$$
\mathrm{LOS}=0.570 \mathrm{MOL}+0.322 * \mathrm{VOL}-0.932 * \mathrm{AST}+0.432 * \mathrm{LOP}, R^{2}=0.473
$$




$\begin{array}{llll}(0.126) & (0.541) & (0.898) & (0.099) \\ 4.847 & 1.426 & -2.166 & 2.862\end{array}$

\subsection{Discussions}

Results from the analysis show that Longan product management and public policy has positive effects on Longan security whereas agricultural science and technology has a negative effect on Longan security, while, value of Longan product has no effect on Longan security. The aforementioned variables can explain the variation of Longan security for 47.3 percent.

\section{Conclusions}

From hypothesis testing, the study found that Longan product management and Longan policy have positive effects on Longan security since Longan farmers have good product management and production cost control. By training the right shape of Longan trees and using low level of Potassium Chlorate, both help

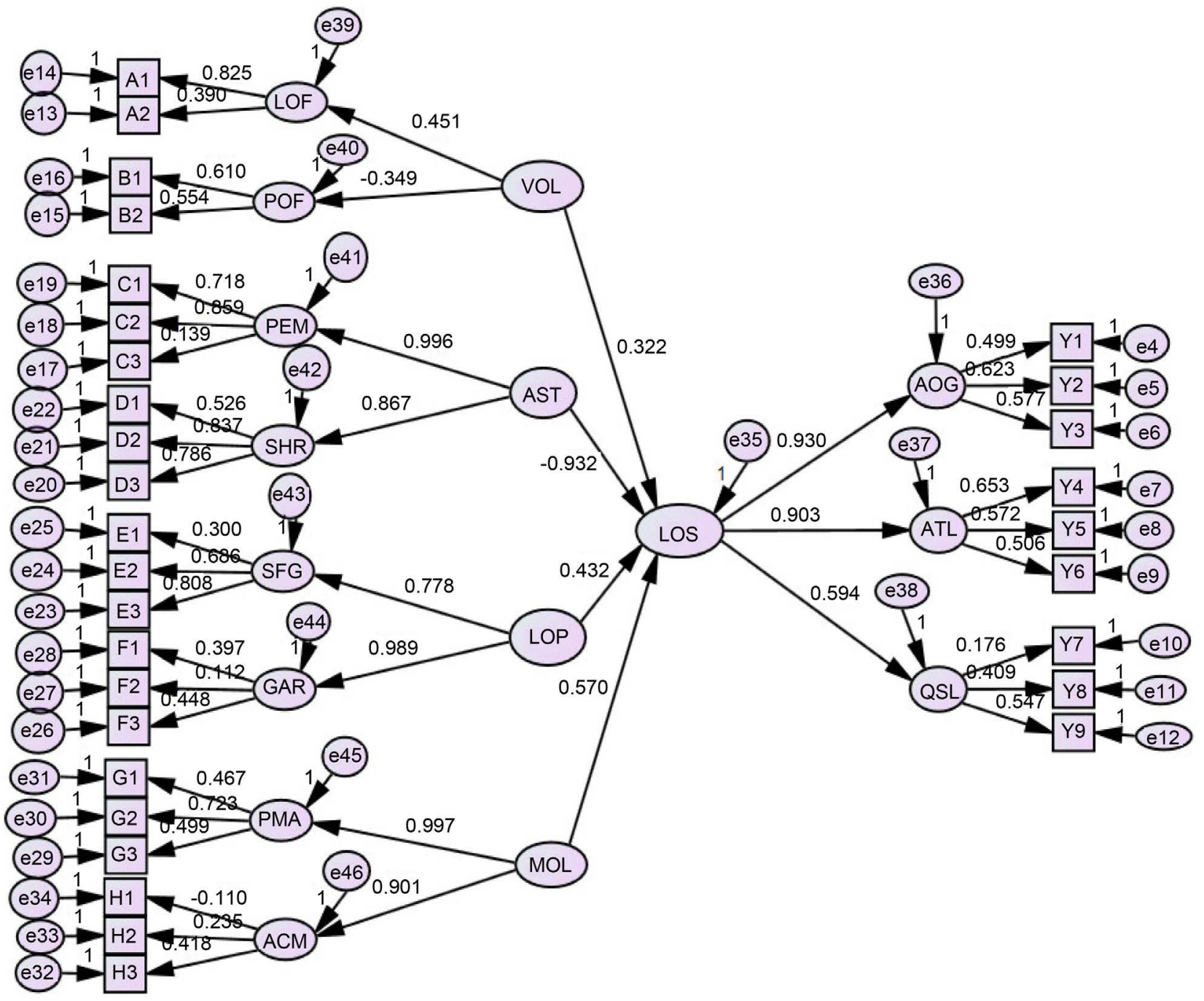

Figure 2. The result of structural equation modeling of Longan security in Thailand. 
Table 1. Model fit indices.

\begin{tabular}{ccc}
\hline Indices & Criteria & Model \\
\hline Chi-square/df & Less than 3.00 & 2.367 \\
RMSEA & Less than 0.08 & 0.047 \\
RMR & Equal to or lower than 0.05 & 0.021 \\
GFI & Greater than 0.90 & 0.923 \\
CFI & Greater than 0.90 & 0.907 \\
PGFI & Greater than 0.50 & 0.620 \\
IFI & No less than 200 & 0.910 \\
\hline
\end{tabular}

produce Longan fruits all year round. Moreover, farmer market helps the farmers learn about transportation and services, distribution channels as well as many aid requests from key ministries. The findings of this research aligned with Premanandh's research [20] which found that Biofuel production, increase in agricultural productivity, ease of market access, and rural farm potential development have effects on food security as well as sufficient investment and cost control in modern farming.

The public policy plays a significant role in Longan security since the policy helps strengthen Longan farmers including environmental-friendly agricultural policy. The public policy is a factor that affects its security, for example, agricultural policy, food pricing, economic development, or agricultural intervention [21].

However, for the employment of agricultural science and technology in pests' elimination, Longan farmers prefer sulfur dioxide fumigation to irradiation due to a higher efficiency in destroying microbial contamination and extending Longan shelf life. However, a problem of high sulfur dioxide residues on Longan exceeding China and USA standards causes the rejection of fruit being $\mathrm{SO}_{2} \mathrm{fu}$ migated and that has put the constraint for exporting Longan from Thailand [14]. With this conclusion, there are few recommendations to be made for future actions.

1) For management, the government needs to support the transportation and service such as infrastructure, transportation and service, and water. The logistics development will help reduce the cost of logistics system for the farmers.

2) Department of Agricultural Extension, the Ministry of Agriculture and Cooperatives must promote and develop the potential of Longan farmers by providing knowledge of producing, fruit processing, value adding, quality developing the products and the processed product from an upstream to midstream and downstream. To do so, the measures and guidelines to support the agriculture, the agricultural technology transfer, and agricultural service provider need to be determined in order to get the consumers' acceptance. As a result, the farmers are able to secure their profession, receive stable income, gain a better quality of life, as well as sustaining their self-dependent status. 


\section{Conflicts of Interest}

The authors declare no conflicts of interest regarding the publication of this paper.

\section{References}

[1] Aphai, W. and Sukwibul, N. (2014) Longan Dripping in Hydrochloric Acid before Export. Journal of Agricultural Research \& Development, 15, 1. (In Thai)

[2] Diczbalis, Y. (2002) Longan Improving Yield and Quality. A Report for the Rural Industries Research and Development Corporation, Queensland Horticulture Institute, Department of Primary Industries.

https://rirdc.infoservices.com.au/downloads/02-135

[3] Susomboon, C. (2015) The Roles of Science, Technology, Innovation In Aiding Agricultural Sector. National Science, Technology, Innovation Policy Office (STI), Bangkok. (In Thai)

[4] Food and Agriculture Organization of the United Nations-FAO (1999) Organic Agriculture. 15 Session, Committee on Agriculture, Rome.

[5] Limnirankula, B., Promburom, P. and Thongngam, K. (2015) Community Participation in Developing and Accessing Household Food Security in the Highlands of Northern Thailand. Agriculture and Agricultural Science Procedia, 5, 52-59. https://doi.org/10.1016/j.aaspro.2015.08.008

[6] Ministry of Agriculture and Cooperatives (2017) Strategies in Driving Policies of Improving Farmers' Quality of Life. (In Thai)

[7] Department of Agricultural Extension (2017) Strategic Plan of the Department of Agricultural Extension 2017-2021. (In Thai)

[8] Thepchitra, K. (2014) 10 Professional Methods in Cost Management Technology and Productivity Improvement. Local Technology Magazine, 27, 66. (In Thai)

[9] Chiti, S., Pimsiri, T., Korawan, S., Sanchai, P., Darunee, N., Soraya, R. and Pittaya, S. (2013) Influence of Water Regimes and Potassium Chlorate on Floral Induction, Leaf Photosynthesis and Leaf Water Potential in Longan. Journal of Agricultural Science, 5, 211-220.

[10] Bangerth, K.F., Potchanasin, P. and Sringarm, K. (2010) Hormonal Regulation of the Regular and "Off Season" Floral Induction Process of Longan (Dimocarpus longan) Trees. Acta Horticulturae, No. 863, 215-224.

https://doi.org/10.17660/ActaHortic.2010.863.28

[11] Senanan, C., Manochai, P., Ussahatanonta, S. and Ongprasert, S. (2010) The Response of Longan Trees to Training System and Fertilizer Management. Acta Horticulturae, ISHS 863, 351-356. http://www.actahort.org/books/863/863_46.htm https://doi.org/10.17660/ActaHortic.2010.863.46

[12] Rich, K.M. and Narrod, C.A. (2006) Market Failures and the Role of Public-Partnerships to Enhance Smallholder Delivery of High-Value Agriculture. http://hdl.handle.net/10568/1183

[13] Honghui, G., et al. (2005) The Hoarding Characteristic of the Longan Fruit with Protect the Fresh Technique Research Make Progress. Review of China Agricultural Science and Technology, 7, 21-24.

[14] Ketsa, S. and Paull, R.E. (2014) Longan: Postharvest Quality-Maintenance Guidelines. Fruit, Nut, and Beverage Crops, 1-3. 
[15] Utto, W., et al. (2008) Hexanal Reduces Infection of Tomatoes by Botrytis cinerea Whilst Maintaining Quality. Postharvest Biology and Technology, 47, 434-437. https://doi.org/10.1016/j.postharvbio.2007.08.008

[16] Soong, Y.Y. and Barlow, P.J. (2006) Quantification of Gallic Acid and Ellagic Acid from Longan Seed and Mango Kernel and Their Effects on Antioxidant Activity. Food Chemistry, 97, 524-530. https://doi.org/10.1016/j.foodchem.2005.05.033

[17] Chanrittisen, T. and Chomsri, N. (2010) Exploring Feasibility for Production of Longan Fruit Wine as a Small-Scale Enterprise in Thailand. Asian Journal of Food and Agro-Industry, 3, 242-247.

[18] Hasachoo, N. and Kalaya, P. (2013) Competitiveness of Local Agriculture: The Case of Longa Fruit Trade between China and the North of Thailand. The Research Institute on Contemporary Southeast Asia (IRASEC), Bangkok.

[19] Yamane, T. (1973) Statistics: An Introductory Analysis. John Weather Hill, London.

[20] Premanandh, J. (2011) Factors Affecting Food Security and Contribution of Modern Technologies in Food Sustainability. Journal of the Science of Food and Agriculture, 91, 2707-2714. https://doi.org/10.1002/jsfa.4666

[21] USAID (2011) USAID’s Legacy Agricultural Development 50 Years of Progress. Bureau for Food Security, Washington DC. 